\title{
Decreased varicella and increased herpes zoster incidence at a sentinel medical deputising service in a setting of increasing varicella vaccine coverage in Victoria, Australia, 1998 to 2012
}

H A Kelly (heath.kelly@mh.org.au) ${ }^{1,2}$, K A Grant ${ }^{1}$, H Gidding ${ }^{3}, K_{\text {S Carville }}{ }^{1}$

1. Victorian Infectious Diseases Reference Laboratory, the Doherty Institute, Melbourne, Australia

2. National Centre for Epidemiology and Public Health, Australian National University Canberra, Australia

3. School of Public Health and Community Medicine, UNSW Medicine, the University of New South Wales, Sydney, Australia

We performed an ecological study using sentinel consultation data from a medical deputising service to assess the impact of increasing coverage with childhood varicella vaccine on the incidence risk of varicella and zoster in the population served by the deputising service in Victoria, Australia from 1998 to 2012. Following a successful vaccination programme, the incidence of varicella in Australia was modelled to decrease and the incidence of zoster to increase, based on a theoretical decrease in boosting of zoster immunity following a decrease in wild varicella virus circulation due to vaccination. Incidence risks (consultation proportions for varicella and zoster) were directly age-standardised to the Melbourne population in 2000, when varicella vaccine was first available. Age-standardised varicella incidence risk peaked in 2000 and halved by 2012. Age-standardised zoster incidence risk remained constant from 1998 to 2002, but had almost doubled by 2012 . The increase in zoster consultations largely reflected increases in people younger than 50 years-old. Although causality cannot be inferred from ecological studies, it is generally agreed that the decrease in varicella incidence is due to increasing varicella vaccine coverage. The possible indirect effect of the vaccine on zoster incidence is less clear and ongoing monitoring of zoster is required.

\section{Introduction}

In 1998 the World Health Organization recommended adding varicella vaccine to routine childhood vaccination schedules where it could be shown to be of relative public health and socio-economic importance, where it was affordable and where sustained coverage could be achieved [1]. The United States had implemented universal childhood varicella vaccination three years earlier, leading to a decline in varicella incidence, related deaths and hospitalisations [2]. In 2004 the European Working Group on Varicella recommended routine varicella vaccination for all healthy children between 12 and 18 months and for all susceptible children before their 13th birthday, and catch-up vaccination in older children and adults without a reliable history of varicella and who were at risk of transmission and exposure [3]. The introduction of varicella vaccine into the childhood schedule with subsequent significant decrease in varicella in the community has been reported from Navarre in Spain [4] and Bavaria in Germany [5] but not all European countries have a universal varicella vaccine programme [6].

Part of the reluctance to introduce universal varicella vaccination in some European countries was related to the theoretical possibility that high coverage with varicella vaccine in children would lead to an increase in zoster. This possibility is based on the hypothesis that T-cell-mediated immunity to zoster is boosted by repeated exposure to circulating wild varicella virus and that this boosting will decrease following the decrease in circulating wild virus due to varicella vaccination. This is known as the Hope-Simpson hypothesis [7]. Assuming this hypothesis to be true, modelling in England [8-10], Finland [11], the United States [12] and Australia [13] suggested an increase in zoster incidence for as many as 60 years would accompany a decrease in varicella incidence following widespread use of varicella vaccine in childhood. Australia nonetheless licensed varicella vaccine in 2000 and added it to the publicly funded national immunisation programme in November 2005 for all children 18 months of age, with a catch-up vaccine for children aged from 10 to 《14 years. From 1 July 2013 the monovalent vaccine was replaced with a combined measles-mumps-rubellavaricella (MMRV) vaccine [14]. Varicella vaccine coverage for children aged less than 2 years in Australia was estimated as $83 \%$ by March 2011 [15] but sufficient doses of vaccine had been distributed in the state of 
Victoria by 2002, prior to public funding, to cover up to $70 \%$ of children aged 12 months and a decline in varicella hospitalisations had been noted from 2000 [16]. Zoster vaccine was not available in Australia during the years of the study (1998 to 2012).

Following the introduction of varicella vaccine, a variety of approaches have been used to monitor varicella and zoster incidence (reviewed in Reynolds et al. [17]). All reviewed studies documented a decrease in varicella incidence but no change, or an increased incidence, in zoster. More recent studies from the United States have shown increases in zoster incidence in age groups ranging from 40 to 65 years, but often these increases were seen before the introduction of varicella vaccine [18-20]. A gradual increase in zoster incidence, both before and after varicella vaccination, has also been seen in Canada [21], Australia [16] and China [22].

Using data from Victoria, Australia's second most populous state (population in 2010 approximately 5.6 million [23]), we have previously demonstrated the predicted decrease in the number of cases hospitalised for varicella and described an increase in the number of hospitalisations for zoster that began before the introduction of varicella vaccine [16]. However, a recent Australian study showed a slight decrease in age-standardised zoster hospitalisations, and noted that trends in non-hospitalised disease would need to be monitored [24]. In the current study we have used community-derived data from 1998 to 2012 from a deputising medical service, fulfilling the role of a general practice sentinel surveillance scheme, to investigate the modelled changes in varicella and zoster incidence related to the introduction of a universal childhood varicella vaccination programme in Australia.

\section{Methods}

We used sentinel data from a Melbourne-based medical deputising service, known as the National Home Doctor Service [25], which provides after-hours (after 4 p.m. on weekdays and at any time during the weekend) medical treatment on behalf of 650 general practices in Melbourne and Geelong, the two largest population centres in Victoria. Deputising service doctors are all general practitioners (GPs), working in a service that has been operating for more than four decades and which was accredited by the Royal Australian College of General Practitioners in 2002. Patients are typically those who would be seen with acute problems in general practice but are instead visited at home or in an aged-care facility. The ageing of the population and increasing demand on GPs to visit elderly patients in their homes or aged-care facility has meant that the deputising service has an increasingly elderly patient base. Total consultations have increased from approximately 73,000 in 1998 to 149,000 in 2012 (data extracted from the deputising service database). GPs enter the details of each consultation into a purposedesigned database that includes a free-text diagnosis field. All entries are subject to quality assurance.

The Victorian Infectious Diseases Reference Laboratory has password-protected access to the clinical database maintained by the deputising service. Ethical approval for the ongoing use of deputising service data for

\section{FIGURE 1}

Deputising service consultations for varicella, age standardised and by age group, Victoria, Australia, 1998-2012

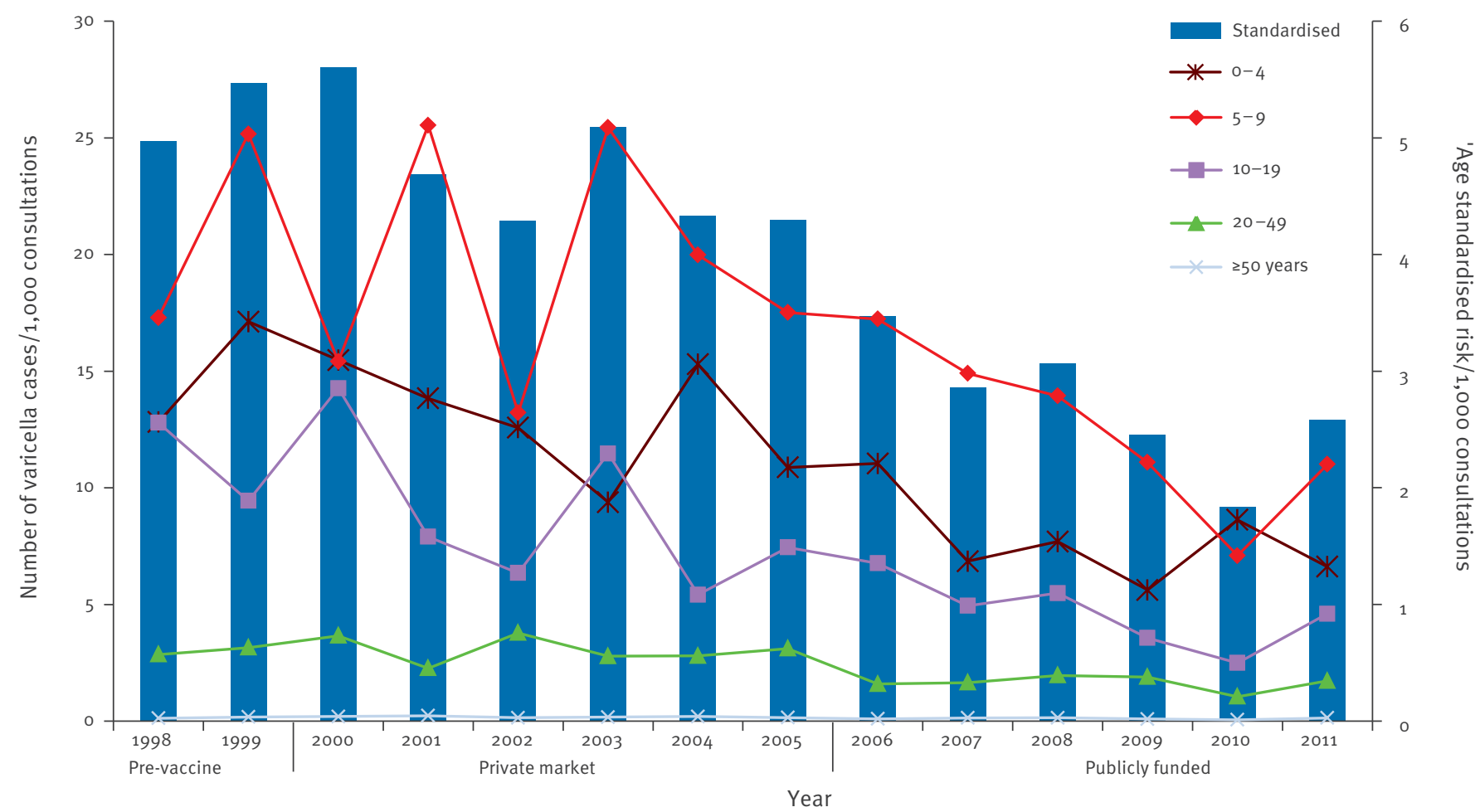


surveillance was granted by the Human Research Ethics Committees at the Victorian Department of Health in October 2002. We conducted searches for consultations with 'chicken'/'varicella' or 'zoster'/'shingles' recorded in the diagnosis field between 1998 and 2012. Data were extracted by week of consultation and age. We grouped the data into the age groups $0-4$, $5-9,10-19,20-49$ and $\geq 50$ years for varicella and $<50$, $50-59,60-69,70-79$ and $\geq 80$ years for zoster and calculated the incidence risk for varicella and zoster as the age-specific proportion of consultations per 1,000 patients (hereafter referred to as the incidence risk) for all study years.

We then directly age-standardised the deputising service consultation proportion (incidence risk) estimates to the Melbourne population in 2000 [23]. We further analysed data according to the three periods of vaccine availability: (i) pre-2000, when no vaccine was available; (ii) 2000-05, when vaccine was available on the private market; and (iii) after 2005, when the vaccine was funded by the national immunisation programme. Proportions were compared using a two-sample test of proportions. Trends in the age-specific and agestandardised proportions over the period of the study were analysed using a non-parametric test for trend developed by Cuzick as an extension of the Wilcoxon rank sum test (STATA version 10.0; StataCorp LP). For all analyses we accepted p<0.05 as the threshold for statistical significance.

\section{Results}

The age-standardised varicella incidence risk rose from 5.0 per 1,000 patients in 1998 to 5.6 per 1,000 patients in $2000(p=0.157)$, and then fell to 2.0 per 1,000 patients in 2012 ( $p$ for trend=0.001 from 1998 to 2012) (Figure 1). In the shorter period from 2005 , since the introduction of varicella vaccine into the publicly funded national immunisation programme, the age-standardised varicella incidence risk fell from 4.3 per 1,000 patients to 2.0 per 1,000 patients in 2012 ( $p$ for trend=0.023). The age-standardised varicella incidence risk decreased significantly over each period of vaccine availability. During the period of no vaccine (1998 to 1999) the incidence risk was 5.2 per 1,000 patients. It subsequently decreased to 4.7 per 1,000 patients during the period of availability on the private market (2000 to 2005) and fell again to 2.5 per 1,000 patients during the period when the vaccine was publicly funded (2006 to 2012) (Table).

Age-group specific varicella incidence risk decreased significantly for all age groups during 2000 to 2012 (p for trend<0.01 for all except those aged 50 years and older, $p=0.02$ ) (Figure 1). Varicella incidence risk calculated for each period of vaccine availability showed

TABLE

Number and proportion per 1,000 consultations of varicella and zoster cases by age group and period of varicella vaccine availability, Victoria, Australia, 1998-2012

\begin{tabular}{|c|c|c|c|}
\hline $\begin{array}{l}\text { Cases by age group in years and age-standardised } \\
\text { risk }\end{array}$ & $\begin{array}{c}1998-99 \\
\text { Pre-vaccine } \\
\text { n (proportion per } \\
1,000 \text { consultations) }{ }^{a}\end{array}$ & $\begin{array}{c}2000-05 \\
\text { Private market } \\
n \text { (proportion per } \\
1,000 \text { consultations) }^{\mathrm{a}}\end{array}$ & $\begin{array}{c}2006-12 \\
\text { Publicly funded } \\
\text { n (proportion per } 1,000 \\
\text { consultations) })^{a}\end{array}$ \\
\hline \multicolumn{4}{|l|}{ Varicella } \\
\hline $0-4$ & $160(14.96)$ & $369(12.84)$ & $415(6.93)^{b, c}$ \\
\hline $10-19$ & $66(11.07)$ & $137(8.75)$ & $128(4.54)^{b, c}$ \\
\hline $20-49$ & $146(3.01)$ & $288(3.10)$ & $205(1.61)^{\mathrm{b}, \mathrm{c}}$ \\
\hline$\geq 50$ & $13(0.16)$ & $45(0.19)$ & $60(0.12)^{c}$ \\
\hline Total & $480(3.06)$ & $1.068(2.67)^{d}$ & $1.073(1.39)^{b, c}$ \\
\hline Age-standardised risk of varicella consultations & 5.22 & $4 \cdot 70^{d}$ & $2.54^{\mathrm{b}, \mathrm{c}}$ \\
\hline$<50$ & $40(0.58)$ & $140(0.94)^{d}$ & $285(1.15)^{b}$ \\
\hline $50-59$ & $15(1.04)$ & $72(2.27)^{d}$ & $152(3.33)^{b, c}$ \\
\hline $60-69$ & $32(2.57)$ & $79(2.46)$ & $200(3.90)^{b, c}$ \\
\hline $70-79$ & $71(3 \cdot 32)$ & $183(3.23)$ & $370(3.75)$ \\
\hline$\geq 80$ & $137(4.03)$ & $429(3.57)$ & $1016(3.15)^{\mathrm{b}, c}$ \\
\hline Total & $295(1.87)$ & $903(2.26)^{d}$ & $2023(2.62)^{b, c}$ \\
\hline Age-standardised risk of zoster consultations & 1.03 & $1.41^{\mathrm{d}}$ & $1.81^{\mathrm{b}, \mathrm{c}}$ \\
\hline
\end{tabular}

Unless otherwise indicated.

p<0.05 for comparison 1998-99 and 2006-12.

p<0.05 for comparison 2000-05 and 2006-12.

p $<0.05$ for comparison $1998-99$ and 2000-05 
small decreases for people aged under 20 years between 1998 to 1999 (no vaccine) and 2000 to 2005 (privately available). However, statistically significant decreases were seen after the vaccine was publicly funded (2006 to 2012) (Table). The age distribution of varicella consultations remained similar over the three periods of different vaccine availability, with the highest proportion of varicella consultations among 5 to 9 year-olds, followed by under 5 year-olds. Varicella consultations remained very uncommon in patients aged at least 50 years (Table).

Changes in zoster incidence risk between 1998 and 2012 were not as clear as those for varicella. Although there was a significant increase in the age-standardised zoster incidence risk, ranging from 1.0 per 1,000 patients in 1998 to 1.8 per 1,000 patients in 2012 (p for trend=0.005), the change was not uniform. The increase was significant in people aged younger than 70 years ( $p$ for trend $<0.01$ for people aged under 60 years and $p$ for trend $=0.02$ for 60-69 year olds (Figure 2)) but there was no increase for people aged 70 years and over. When the data were collapsed into the three periods of vaccine availability, the incidence risk for those aged less than 70 years increased, consistent with the trend data (Table 1). However, a significant decrease was seen in zoster incidence risk of cases aged 80 years and older across each period of vaccine availability (Table).

\section{Discussion}

In the 15 years from 1998 to 2012, the age-standardised varicella incidence risk, estimated from medical consultations at the deputising service, halved while the age-standardised incidence risk of zoster almost doubled. Both changes were statistically significant when analysed according to distinct periods of vaccine availability. We have used consultation proportions as a measure of incidence risk in a specific patient group because we were unable to determine the population base of the deputising service and thus were not able to calculate population-based incidence rates. However, the recent study from Bavaria, Germany, also used population proportions in sentinel paediatric practices to describe a change in the varicella infection pattern in the community [5]. The decrease in varicella incidence risk is consistent with our previous results based on hospital discharge data [16] and reports from other countries $[4,5,26]$.

We have also previously reported an increase in zoster incidence in hospital data, as predicted by modelling [13], largely driven by an increase in those aged over 80 years [16]. Deputising service data by age were not available to us at the time of our earlier report, and the overall number of zoster consultations (not age standardised) was observed to increase from 2001 [16]. Although the deputising service data reported here indicate variability in zoster consultations, we have described a clear increasing trend in presentations for zoster in community patients younger than 70 years, and found some indication of a decreased number of consultations for zoster in the community among those aged 80 years and older. A mixed picture of age-related changes in zoster has been reported from various data sources in various countries $[18,19,27,28]$. However, compared with many other countries, Australia has relatively high childhood varicella vaccine coverage,

\section{FIGURE 2}

Deputising service consultations for zoster, age standardised and by age group, Victoria, Australia, 1998-2012

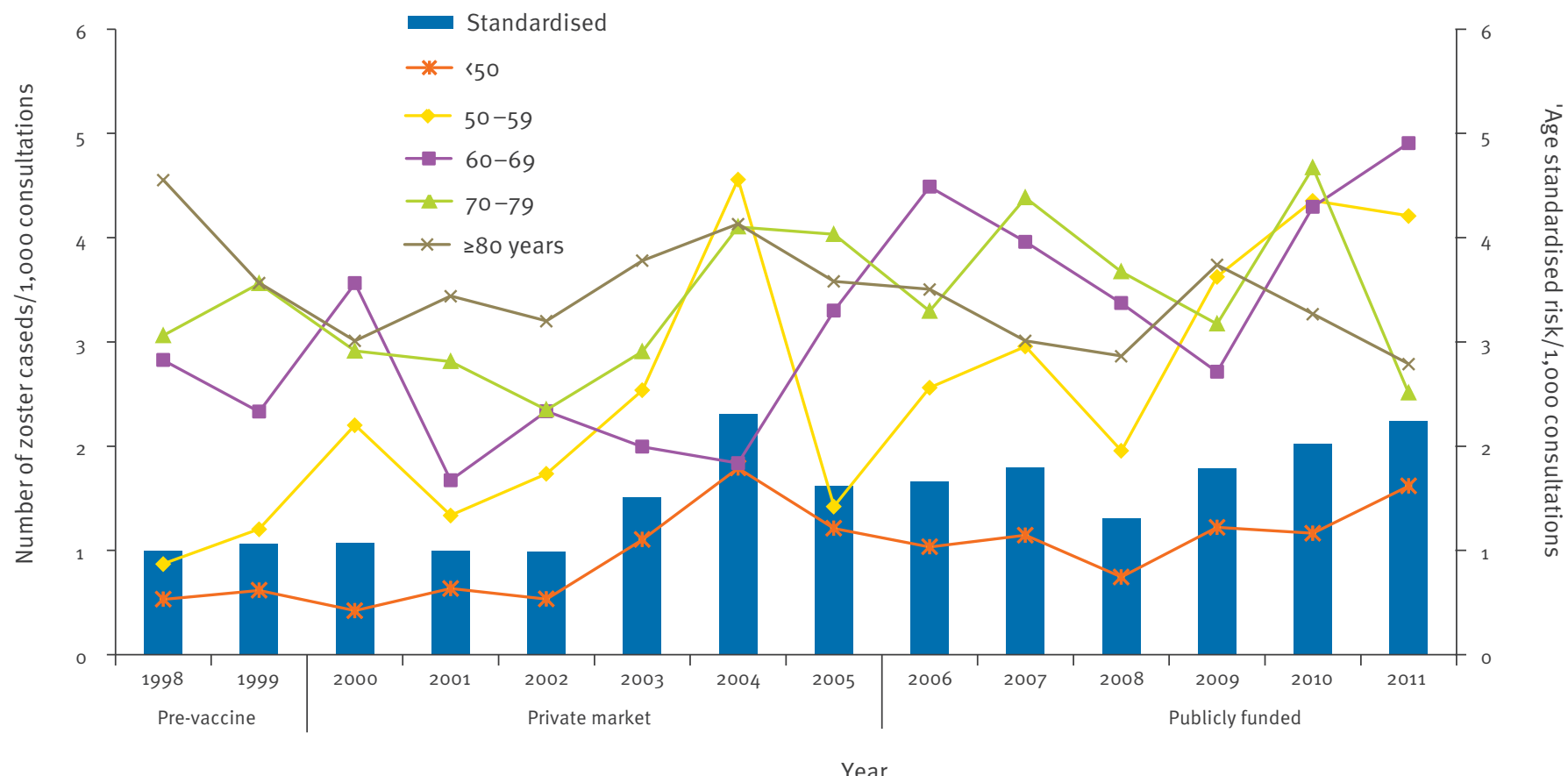


which may impact on zoster, as well as varicella, incidence. An increase in zoster incidence among younger patients, for any reason, may be easier to detect in the community, since these patients will be less likely to require hospitalisation for zoster and may not be detected in studies of inpatients. On the other hand, changes in zoster incidence among older patients, especially those older than 80 years, may be easier to detect in hospitalised patients $[16,24]$, whether due to disease severity or changed thresholds for hospital admissions among the elderly.

Our study has a number of limitations. The feasibility of using general practice sentinel surveillance to monitor varicella and zoster has recently been demonstrated in Spain [29], but a deputising service is not often used for sentinel surveillance. However Victorian data from the National Home Doctor Service have previously demonstrated comparable evidence on influenza-like illness in the community to that provided by other sentinel practices in Victoria [30]. We have recently extended this comparison to revise thresholds for influenza surveillance in Victoria and have demonstrated that the two sentinel systems detect influenza community circulation within one week of each other [31]. The deputising service is also used to monitor gastroenteritis in the community in Victoria and has shown concordance between gastrointestinal illnesses seen by GPs from the deputising service and community-based outbreaks due to norovirus [32]. The concordance between sentinel deputising service and sentinel general practice surveillance for influenza-like illness and gastroenteritis demonstrates the applicability of the deputising service to community-based surveillance of infectious diseases.

Surveillance detects only a proportion of all disease. Less severe cases of varicella and zoster are not likely to present to any medical service, including the deputising service, while more severe cases will present to a hospital. There are also differences between the deputising service and clinic-based general practice. Whereas the five most common reasons for presentations to Australian general practices in 2009-10 were for prescriptions, a general check-up, having a pathology test or reviewing results, providing an immunisation and fever [33], the five most common reasons for deputising service consultations were falls, respiratory tract infection, review (unspecified), gastroenteritis and urinary tract infection (data extracted from the deputising service database). This difference confirms that the deputising service is more likely to see patients with an acute problem. However changes in those who consult, in treatment-seeking behaviour or the healthcare system could have influenced the trends we have reported.

The deputising service covers most of the Melbourne and Geelong metropolitan areas, which includes a large and diverse population. Data on socio-economic status or other determinants of health are not routinely collected by the deputising service. While people who use the deputising service may not be representative of those who consult in general, there is no financial disincentive to use the deputising service, as consultations are free to the patient at the time of consultation. This has not changed during the study period. The population base for deputising service consultations among those aged less than 50 years remained relatively constant over the study period, making it likely that the increase in zoster consultations seen in this age group is not a result of overall changes in the proportion of this age group consulting.

However, the proportion of older patients seen by the deputising service GPs increased substantially. In $2000,25 \%(14,947 / 60,329)$ of patients were aged 80 years and above, but this had increased to $39 \%$ $(61,110 / 157,025)$ by 2012 . These variations do not affect trends in proportions within age groups and we have controlled for these changes in summary data by direct age standardisation to the Melbourne population in 2000.

We did not validate the diagnosis fields used by the deputising service and it is possible that the search algorithm may generate some false positives where entries such as 'query chickenpox' would be counted as an episode of varicella. However, we extracted the same diagnosis terms for all years, assuming biases and anomalies that might be present would not change by year. Quality assurance should minimise misspelling that may otherwise result in missed records using text-based search terms.

Although ecological studies cannot be used to infer causality they are nonetheless used as evidence to support the success of vaccination programmes, including the childhood varicella programme in Victoria and elsewhere. Where the relationship is less direct, as with varicella vaccination and zoster, it is more difficult to make an inferential connection. We are not able to conclude that the increase in zoster incidence risk in community patients seen by the deputising service GPs is caused by high coverage with varicella vaccine, as has been suggested by modelling studies. Equally, we cannot conclude that increasing varicella vaccine coverage does not, or will not, play a role in transient increasing zoster incidence within the community. These community-based data add to growing evidence of increasing zoster - for whatever reason - and highlight the need for multiple surveillance systems that track different population groups or different levels of illness severity for the decades over which zoster is modelled to change $[9,12,24]$. The increase in zoster suggests that the introduction of an adult zoster vaccination programme could be beneficial, depending on the age of vaccine administration, the effectiveness of the vaccine and the duration of protection [34]. 


\section{Acknowledgements}

We gratefully acknowledge the support of Ms Josie Adams, former Executive Director of the Melbourne Medical Deputising Service, now known as the National Home Doctor Service, and Adam Wilson for the continued involvement of the National Home Doctor Service. We also thank Dr Sheena Sullivan for her statistical advice. The evaluation of the varicella vaccine programme is supported by the Victorian Government Department of Health.

\section{Conflict of interest}

None declared.

\section{Authors' contributions}

Conceived the idea: KG, HK. Designed the analysis: HK, KC, KG. Performed the analysis: KC, KG. Wrote the paper: HK, KC, KG, HG. Approved the final version: HK, KG, HG, KC.

\section{References}

1. Varicella vaccines. WHO position paper. Wkly Epidemiol Rec. 1998;73(32):241-8

2. Schmid DS, Jumaan AO. Impact of varicella vaccine on varicellazoster virus dynamics. Clin Microbiol Rev. 2010;23(1):202-17. http://dx.doi.org/10.1128/CMR.00031-09

3. Rentier B, Gershon AA; European Working Group on Varicella. Consensus: varicella vaccination of healthy children--a challenge for Europe. Pediatr Infect Dis J. 2004;23(5):379-89. http://dx.doi.org/10.1097/01.inf.0000122606.88429.8f

4. Garcia Cenoz M, Castilla J, Chamorro J, Martinez-Baz I, Martinez-Artola V, Irisarri F, et al. Impact of universal two-dose vaccination on varicella epidemiology in Navarre, Spain, 2006 to 2012. Euro Surveill. 2013;18(32): pii=20552.

5. Streng A, Grote V, Carr D, Hagemann C, Liese JG. Varicella routine vaccination and the effects on varicella epidemiology - results from the Bavarian Varicella Surveillance Project (BaVariPro), 2006-2011. BMC Infect Dis. 2013;13:303. http:// dx.doi.org/10.1186/1471-2334-13-303

6. Stefanoff P, Polkowska A, D'Ancona FP, Giambi C, Bruhl DL, O'Flanagan D, et al. Varicella and herpes zoster surveillance and vaccination recommendations 2010-2011. VENICE II Consortium, 2010. Available from: http://venice.cineca.org/ report_final_varicella.pdf

7. Hope-Simpson RE. The nature of herpes zoster: a long-term study and a new hypothesis. Proc R Soc Med. 1965;58:9-20.

8. van Hoek AJ, Melegaro A, Zagheni E, Edmunds WJ, Gay N. Modelling the impact of a combined varicella and zoster vaccination programme on the epidemiology of varicella zoster virus in England. Vaccine. 2011;29(13):2411-20. http://dx.doi. org/10.1016/j.vaccine.2011.01.037

9. Brisson M, Edmunds WJ, Gay NJ, Law B, De Serres G. Modelling the impact of immunization on the epidemiology of varicella zoster virus. Epidemiol Infect. 2000;125(3):651-69. http:// dx.doi.org/10.1017/So950268800004714

10. Brisson M, Edmunds WJ, Law B, Gay NJ, Walld R, Brownell M, et al. Epidemiology of varicella zoster virus infection in Canada and the United Kingdom. Epidemiol Infect. 2001;127(2):305-14. http://dx.doi.org/10.1017/S0950268801005921

11. Karhunen M, Leino T, Salo H, Davidkin I, Kilpi T, Auranen K. Modelling the impact of varicella vaccination on varicella and zoster. Epidemiol Infect. 2010;138(4):469-81. http://dx.doi. org/10.1017/S0950268809990768

12. Schuette MC, Hethcote HW. Modeling the effects of varicella vaccination programs on the incidence of chickenpox and shingles. Bull Math Biol. 1999;61(6):1031-64. http://dx.doi. org/10.1006/bulm.1999.0126

13. Gidding HF, Brisson M, Macintyre CR, Burgess MA. Modelling the impact of vaccination on the epidemiology of varicella zoster virus in Australia. Aust N Z J Public Health. 2005;29(6):544-51. http://dx.doi.org/10.1111/j.1467842X.2005.tbo0248.X

14. Australian Government Department of Health and Ageing. The Australian immunisation handbook. 10th ed. Canberra: Commonwealth of Australia; 2013. Available from: http://www. health.gov.au/internet/immunise/publishing.nsf/Content/ Handbook10-copyright
15. Ward K, Dey A, Hull B, Quinn HE, Macartney K, Menzies R. Evaluation of Australia's varicella vaccination program for children and adolescents. Vaccine. 2013;31(10):1413-9. http:// dx.doi.org/10.1016/j.vaccine.2012.12.052

16. Carville KS, Riddell MA, Kelly HA. A decline in varicella but an uncertain impact on zoster following varicella vaccination in Victoria, Australia. Vaccine. 2010;28(13):2532-8. http://dx.doi. org/10.1016/j.vaccine.2010.01.036

17. Reynolds MA, Chaves SS, Harpaz R, Lopez AS, Seward JF. The impact of the varicella vaccination program on herpes zoster epidemiology in the United States: a review. J Infect Dis. 2008;197 Suppl 2:S224-7. http://dx.doi.org/10.1086/522162

18. Rimland D, Moanna A. Increasing incidence of herpes zoste among Veterans. Clin Infect Dis. 2010;50(7):1000-5. http:// dx.doi.org/10.1086/651078

19. Leung J, Harpaz R, Molinari NA, Jumaan A, Zhou F. Herpes zoster incidence among insured persons in the United States, 1993-2006: evaluation of impact of varicella vaccination. Clin Infect Dis. 2011;52(3):332-40. http://dx.doi.org/10.1093/cid/ ciq077

20. Hales CM, Harpaz R, Joesoef MR, Bialek SR. Examination of links between herpes zoster incidence and childhood varicella vaccination. Ann Intern Med. 2013;159(11):739-45. http:// dx.doi.org/10.7326/0003-4819-159-11-201312030-00006

21. Russell ML, Dover DC, Simmonds KA, Svenson LW. Shingles in Alberta: Before and after publicly funded varicella vaccination. Vaccine. 2013. pii: So264-410X(13)01249-8.

22. Wu PY, Wu HD, Chou TC, Sung FC. Varicella vaccination alters the chronological trends of herpes zoster and varicella. PloS One. 2013;8(10):e77709. http://dx.doi.org/10.1371/journal. pone.0077709

23. Australian Bureau of Statistics (ABS). 3101.0 - Australian demographic statistics, Sep 2011. Canberra: ABS [Accessed 30 Jun 2011]. Available from: http://www.abs.gov.au/ausstats/ abs@.nsf/mf/3101.0/

24. Heywood AE, Wang H, Macartney KK, McIntyre P. Varicella and herpes zoster hospitalizations before and after implementation of one-dose varicella vaccination in Australia: an ecological study. Bull World Health Organ. 2014;92(8):593-604. http:// dx.doi.org/10.2471/BLT.13.132142

25. National Home Doctor Service. [Accessed 10 Jan 2014]. Available from: http://www.homedoctor.com.au/

26. Marin M, Meissner HC, Seward JF. Varicella prevention in the United States: a review of successes and challenges. Pediatrics. 2008;122(3):e744-51. http://dx.doi.org/10.1542/ peds.2008-0567

27. Russell ML, Schopflocher DP, Svenson L, Virani SN. Secular trends in the epidemiology of shingles in Alberta. Epidemiol Infect. 2007;135(6):908-13. http://dx.doi.org/10.1017/ So950268807007893

28. Jardine A, Conaty SJ, Vally H. Herpes zoster in Australia: evidence of increase in incidence in adults attributable to varicella immunization? Epidemiol Infect. 2011;139(5):658-65. http://dx.doi.org/10.1017/So950268810001949

29. Pérez-Farinós N, Ordobás M, García-Fernández C, GarciaComas L, Ca-ellas S, Rodero I, et al. Varicella and herpes zoster in Madrid, based on the Sentinel General Practitioner Network: 1997-2004. BMC Infect Dis. 2007;7:59. http://dx.doi. org/10.1186/1471-2334-7-59

30. Coory M, Grant K, Kelly H. Influenza-like illness surveillance using a deputising medical service corresponds to surveillance from sentinel general practices Euro Surveill. 2009;14(44):pii=19387.

31. Tay EL, Grant K, Kirk M, Mounts A, Kelly H. Exploring a proposed WHO method to determine thresholds for seasonal influenza surveillance. PloS One. 2013;8(10):e77244. http:// dx.doi.org/10.1371/journal.pone.0077244

32. Victorian Infectious Diseases Reference Laboratory (VIDRL). Norovirus surveillance 2013. Melbourne: VIDRL. [Accessed 15 Mar 2013]. Available from: http://www.vidrl.org.au/ surveillance/norovirus-surveillance/

33. Britt H, Miller GC, Charles J, Henderson J, Bayram C, Pan Y, et al. General practice activity in Australia 2009-10. General practice series number 27. Canberra: Australian Institute of Health and Welfare (AIHW); 2010. Available from: http://www. aihw.gov.au/WorkArea/DownloadAsset.aspx?id=6442472722

34. Hales CM, Harpaz R, Ortega-Sanchez I, Bialek SR; Centers for Disease Control and Prevention (CDC). Update on recommendations for use of herpes zoster vaccine. MMWR Morb Mortal Wkly Rep. 2014;63(33):729-31. 